\title{
A comprehensive analysis of phenological changes in forest vegetation of the Funiu Mountains, China
}

\author{
ZHU Wenbo, ZHANG Xiaodong, ZHANG Jingjing, ZHU Lianqi \\ College of Environment and Planning, Henan University, Kaifeng 475004, Henan, China
}

\begin{abstract}
This paper reports the phenological response of forest vegetation to climate change (changes in temperature and precipitation) based on Moderate Resolution Imaging Spectroradiometer (MODIS) Enhanced Vegetation Index (EVI) time-series images from 2000 to 2015. The phenological parameters of forest vegetation in the Funiu Mountains during this period were determined from the temperature and precipitation data using the Savitzky-Golay filter method, dynamic threshold method, Mann-Kendall trend test, the Theil-Sen estimator, ANUSPLIN interpolation and correlation analyses. The results are summarized as follows: (1) The start of the growing season (SOS) of the forest vegetation mainly concentrated in day of year (DOY) 105-120, the end of the growing season (EOS) concentrated in DOY 285-315, and the growing season length (GSL) ranged between 165 and 195 days. There is an evident correlation between forest phenology and altitude. With increasing altitude, the SOS, EOS and GSL presented a significant delayed, advanced and shortening trend, respectively. (2) Both SOS and EOS of the forest vegetation displayed the delayed trend, the delayed pixels accounted for $76.57 \%$ and $83.81 \%$ of the total, respectively. The GSL of the forest vegetation was lengthened, and the lengthened pixels accounted for $61.21 \%$ of the total. The change in GSL was mainly caused by the decrease in spring temperature in the region. (3) The SOS of the forest vegetation was significantly partially correlated with the monthly average temperature in March, with most correlations being negative; that is, the delay in SOS was mainly attributed to the temperature decrease in March. The EOS was significantly partially correlated with precipitation in September, with most correlations being positive; that is, the EOS was clearly delayed with increasing precipitation in September. The GSL of the forest vegetation was influenced by both temperature and precipitation throughout the growing season. For most regions, GSL was most closely related to the monthly average temperature and precipitation in August.
\end{abstract}

Keywords: phenology; temperature and precipitation; Funiu Mountains; AUSPLAIN interpolation

\section{Introduction}

Climate change has important effects on terrestrial ecosystems by altering plant photosyn-

Received: 2018-04-17 Accepted: 2018-06-20

Foundation: National Natural Science Foundation of China, No.41671090; National Basic Research Program (973 Program), No.2015CB452702

Author: Zhu Wenbo (1989-), PhD, specialized in the mountain ecosystem service, development and utilization of regional natural resources. E-mail: zhuwb517@163.com 
thesis, growth phases, soil formation processes, and nutrient availability (Ivan et al., 2018). The impacts of climate change are amplified in fragile ecosystems, especially in mountainous and coastal areas (King, 2004; Wang et al., 2011; Zhang et al., 2016; Zhu et al., 2016; Jordan et al., 2017). As an important component of mountain ecosystems, forest vegetation is sensitive to climate change. The phenology of mountain forest vegetation, which is a significant indicator of climate change, can reveal the dynamics of mountain vegetation growth processes and reflect the response and adaption of mountain ecosystems to global change; thus, phenology has become the focus of many mountain geography and ecology investigations (Jong et al., 2011; Zhu et al., 2011; Mu et al., 2012). Studying the phenological feedback of different types of forest vegetation to climate change and analyzing the dominant factors that influence phenological changes can help determine the mechanisms of geographical environmental changes in mountain areas and the functional consequences of such changes.

Forest vegetation phenology is the timing of developmental stages in its cycle, including bud burst, flowering, and senescence, which are closely linked to various environmental factors (Zhu et al., 1999; Kong et al., 2017; Luo et al., 2017). Long-term field observations have indicated that vegetation phenology has changed significantly with global warming. In particular, changes in spring temperatures have directly affected germination and flowering time. When spring temperature in Europe increased by $1^{\circ} \mathrm{C}$, flowering time advanced by four days, and germination time advanced by 3.2-3.6 days; when the annual average temperature of the broad-leaved deciduous forest areas in the Eastern United States increased by $1^{\circ} \mathrm{C}$, its growing season increased by 5 days (Zhang et al., 2004). At the hemispheric scale, although the National Oceanic and Atmospheric Administration has used remote sensing satellites such as the Advanced Very High Resolution Radiometer (AVHRR) to conduct a 20 -year observation and found evidence of afforestation changes in the Northern Hemisphere, the regional observation of vegetation phenological changes in the context of global warming remains insufficient (Zhou et al., 2001; Nemani et al., 2003). The monitoring of regional vegetation phenology primarily involves traditional field observations and remote sensing. In the context of global warming, $\mathrm{Xu}$ et al. (2015) analyzed the phenological changes in different types of vegetation in Harbin and found that the germination date was substantially affected by an increase in average spring temperature (Xu et al., 2015). Ma et al. (2016) applied the dynamic threshold method to Global Inventory Modeling and Mapping Studies (GIMMS) Normalized Difference Vegetation Index (NDVI) remote sensing data to study the pattern of phenological change in the Tibetan Plateau from 1982 to 2005. The results showed that temperature played a more influential role in phenological change than precipitation (Ma et al., 2016). Zu et al. (2016) used GIMMS AVHRR remote sensing data to analyze the phenological response to climate change in northeastern China. They reported that temperature was more important to vegetation growth in spring, whereas precipitation was more important in autumn. Most studies that have used remote sensing data analyses to investigate vegetation phenology obtained key parameters through NDVI. However, the accuracy of these determined parameters could be undermined because NDVI is easily saturated and sensitive to soil background and other noises. The enhanced vegetation index (EVI) can effectively improve the accuracy of the examined parameters.

At the hemispheric and continental scales, a number of studies have examined changes in vegetation phenology in response to global warming. However, due to the inherent high diversity in terrestrial ecosystems, there are variations in the phenological responses to global 
change. To study the pattern in these variations, the vegetation in the Funiu Mountains was investigated in this study. This region is located in the transition zone between the north subtropical zone and the warm temperate zone and is known for its large physical geographical gradient, complicated evolutionary processes, and fragile ecosystems (Ma, 2004; Ding et al., 2006; Fan et al., 2008; Zhang et al., 2016). Based on the Savitzky-Golay (S-G) filter algorithm, the phenology parameters of forest vegetation from 2000 to 2015 were extracted. Combined with temperature and precipitation data, these parameters were used to analyze the characteristics of phenological change in the various types of forest vegetation and their relationship to temperature and precipitation. The multidimensional changes in phenology in response to climate change in the Funiu Mountains were also examined.

\section{Research area and data analyses}

\subsection{Research area}

The Funiu Mountains are located in western Henan Province and lie at $110^{\circ} 30^{\prime}$ to $113^{\circ} 30^{\prime} \mathrm{E}$, $32^{\circ} 45^{\prime}$ to $34^{\circ} 20^{\prime} \mathrm{N}$ (Figure 1). The study area includes eight counties: Luanchuan, Songxian, Lushan, Xixia, Neixiang, Zhenping, Lushi, and Nanzhao. The elevation ranges from 45 to $2150 \mathrm{~m}$ asl. The average annual temperature is between $12.1^{\circ} \mathrm{C}$ and $15.1^{\circ} \mathrm{C}$, and the total precipitation fluctuates from 800 to $1100 \mathrm{~mm}$, most precipitation falls during May to September. The mountains lie in the transitional zone from the second to the third step in Chinese topography; they have highly diverse physical geographic landscapes along with complex climatic and geomorphological conditions. Accordingly, the varied transition-type vegetation changes from southern warm-temperate deciduous broad-leaved forests to northern subtropical mixed evergreen and deciduous broad-leaved forests. The main soil types in this region are brunisolic, yellow brunisolic, and cinnamon. The thin soil layers, undulating terrain, and poor trees growing conditions result in a vulnerable ecosystem (Song et al., 1994).
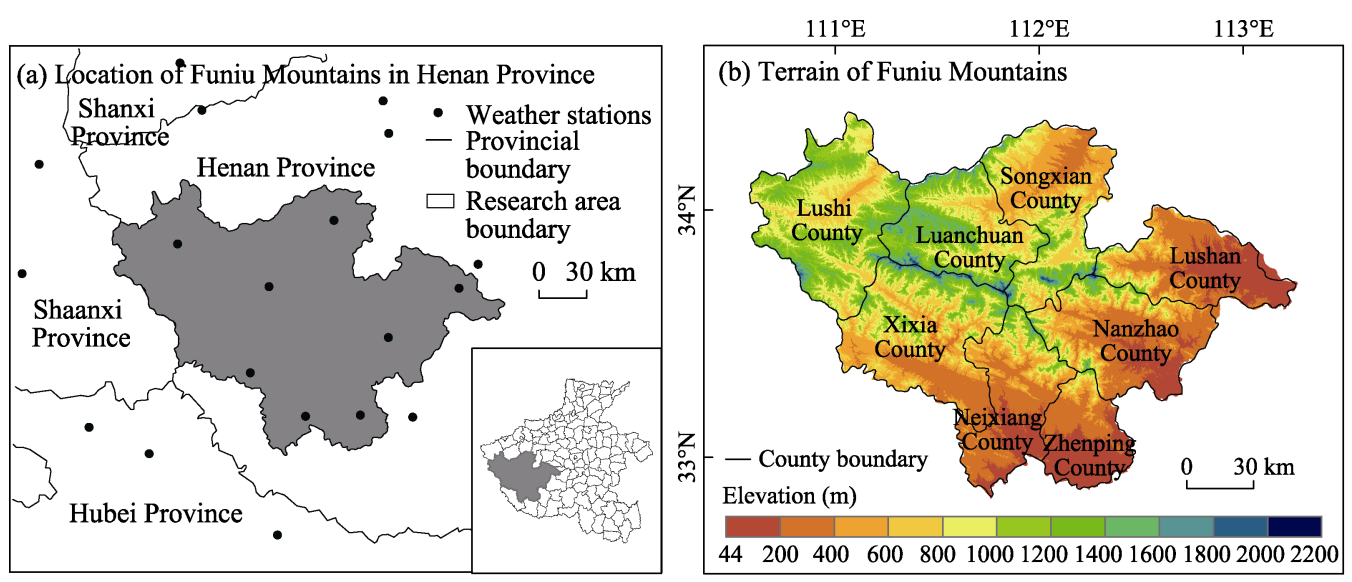

Figure 1 Location of the research area and topography

\subsection{Data extraction and analyses}

\subsubsection{EVI data}

The Moderate Resolution Imaging Spectroradiometer (MODIS) Enhanced Vegetation Index 
(EVI) data used in this study were obtained from the National Aeronautics and Space Administration MOD13Q1 datasets for 2000-2015 at a spatial resolution of $250 \mathrm{~m}$ and a temporal resolution of $16 \mathrm{~d}$. The MODIS Reprojection Tool was used to extract the EVI data from the MOD13Q1 datasets and to perform the reprojection.

We used the dynamic threshold method in the TIMESAT program (Jönsson et al., 2002, 2004) to analyze the start of the growing season (SOS), the growing season length (GSL), and the end of the growing season (EOS) for forest vegetation in the Funiu Mountains from 2000 to 2015.

\subsubsection{Meteorological data}

Meteorological data of the research area and its surroundings, including monthly mean temperature and monthly precipitation from 2000 to 2015, were downloaded for 14 stations of the China Meteorological Administration (www.sci-data.cma.gov.cn). To more precisely analyze the fluctuations of hydrothermal conditions in the Funiu Mountains, data from five stations of the Henan Meteorological Bureau were acquired. Considering the phenological growth cycle of forest vegetation in the Funiu Mountains, an interpolation of the meteorological data was conducted for the period from February to November.

\subsubsection{Other data}

In this paper, elevation and other topographic features were extracted from a digital elevation model (DEM) at $30 \mathrm{~m}$ resolution (ASTER GDEM V2). Based on ENVI V5.1, the DEM images were mosaicked, and the resultant DEM data were then reprojected and resampled to $250 \mathrm{~m}$. Finally, using ArcGIS (V10.1), we used the vector data of the study area boundary to extract the topographic feature attributes data of the Funiu Mountains.

\subsection{Methodology}

\subsubsection{Remote sensing extraction method of forest vegetation phenology}

First, the S-G filtering method in the TIMESAT package was used to smooth the EVI images from 2000 to 2015. Next, the date of EVI increase or decrease to $50 \%$ of the EVI amplitude was defined as the SOS or EOS, respectively. The parameters of forest vegetation phenology (SOS, EOS, and GSL) were extracted based on pixels from the study area from 2000 to 2015. GSL was defined as the difference between EOS and SOS. The conversion of forest vegetation phenological period adopted the Julian calendar; that is, the phenological period was the actual number of days from January 1.

\subsubsection{Recognition method of forest vegetation}

Huanjing satellites are widely used to obtain information on vegetation cover (Wang et al., 2013). Adopting an object-based method for vegetation classification avoids effects caused by the "same object with different spectrum", "different objects with the same spectrum", and "salt and pepper noise." The vegetation in the Funiu Mountains was classified as evergreen broad-leaved forest, evergreen coniferous forest, deciduous broad-leaved forest, deciduous coniferous forest, mixed deciduous-coniferous forest, deciduous broad-leaved forest, and mixed evergreen-deciduous forest (Figure 2). To validate the classification accuracy, 120 random sample points were selected and assessed. The total accuracy reached $85 \%$ with a kappa coefficient of 0.8 , which met the required standard. Due to the long cycles of regen- 
eration and succession of forest vegetation in mountainous areas along with the limited scope of spatial variation in mountain areas, these classification data were considered appropriate for this investigation.

2.3.3 Method of meteorological interpolation

Australian scholar Hutchinson developed the ANUSPLIN software, which can be used for the spatial interpolation of meteorological factors and is particularly suitable for

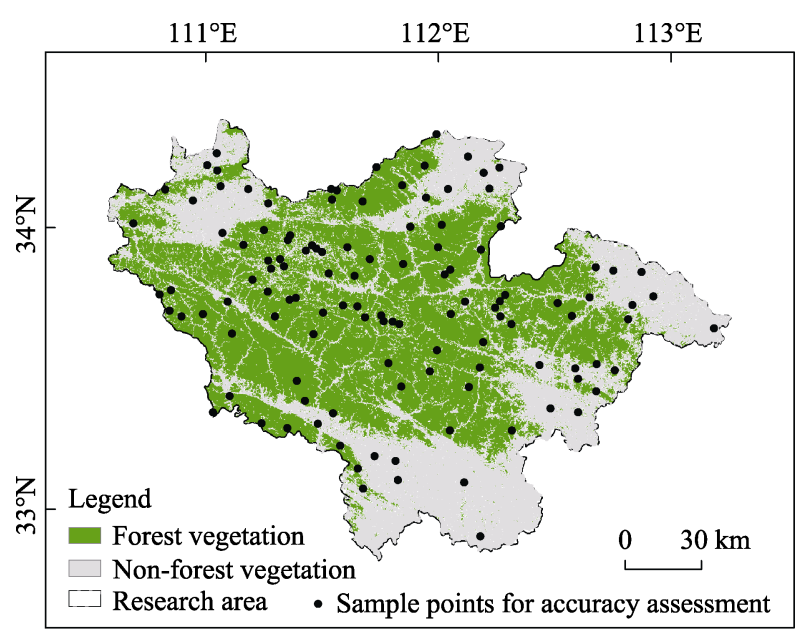

Figure 2 Forest vegetation types in the research area processing time series of meteorological data (Liu et al., 2008). Under the complex mountain environment, the interpolation of temperature and precipitation data using ANUSPLIN is highly accurate (Yu et al., 2008). Tan used ANUSPLIN for temperature interpolation in the complex surface of the Tibetan Plateau and obtained a mean square error of only $0.82^{\circ} \mathrm{C}$ (Tan et al., 2016). Therefore, in this study, we selected ANUSPLIN for the interpolation of monthly average temperature and precipitation from February to November of 2000 to 2015. The spline number was 2 , and the longitude, latitude and elevation were covariates.

\subsubsection{Analysis of trend and correlation}

In this study, the Theil-Sen (T-sen) estimator method was used to determine the variation in the SOS, EOS, and GSL of forest vegetation in the Funiu Mountains (Sen, 1968). T-sen >0 indicates that the phenological parameter was delayed or extended, whereas T-sen $<0$ indicates that the phenological parameter was advanced or shortened. Meanwhile, a Mann-Kendall (M-K) trend test was conducted (95\% confidence level) (And et al., 2006). According to the results of the T-sen and M-K tests, the inter-annual variation in the forest vegetation phenology of the Funiu Mountains was classified as follows: significantly delayed or extended (T-sen $>0, p<0.05$ ); significantly advanced or shortened (T-sen $<0, p<$ 0.05 ); not significantly delayed or extended (T-sen $>0, P>0.05$ ); and not significantly advanced or shortened (T-sen $<0, p>0.05)$.

The Pearson correlation, partial correlation and significance test, among response characteristics of forest vegetation phenology with monthly mean temperature, precipitation from February to November, in the Funiu Mountains were analyzed. The following correlations were evaluated: SOS with monthly mean temperature, precipitation in February, precipitation in March, and precipitation in April; EOS with monthly mean temperature, precipitation in September, precipitation in October, and precipitation in November; and GSL with monthly mean temperature, precipitation in May, precipitation in June, precipitation in July, precipitation in August, and precipitation in September. To analyze the effects of temperature and precipitation on Funiu forest phenology, ENVI/IDL procedures were used to compose the multiband correlation coefficient among forest vegetation phenology with temperature, precipitation in different months, recognize the largest absolute value month of 
correlation coefficient, and mark whether the pixel is a positive effect or negative effect on forest vegetation phenological period.

\section{Results}

\subsection{Average phenological period of forest vegetation}

To study the spatial pattern of forest vegetation phenological period in the Funiu Mountains, the spatial distributions and trends in the SOS, EOS, and GSL of forest vegetation over 16 years were evaluated (Figure 3). The SOS dates of forest vegetation at different elevations from 2000 to 2015 exhibited a delaying trend moving from the peripheral to the central areas in the Funiu Mountains; vegetation in the peripheral areas entered the growing season earlier from approximately day of year (DOY) 105 to 120 (around late April), while vegetation in the central areas entered the growing season later at approximately DOY 120 to 135 (around early May) (Figure 3a). In addition, areas with SOS in the range of DOY 90 to 105 were mostly distributed in the eastern and southern parts. From Figure 3b, it can be seen that the EOSs in the southern and eastern low-altitude areas are the latest, mainly from DOY 300 to 315, while DOY ranges from 285 to $300 \mathrm{~d}$ in other regions. The GSL of forest vegetation shortened from the peripheral to the central part of the Funiu Mountains (Figure 3c). The
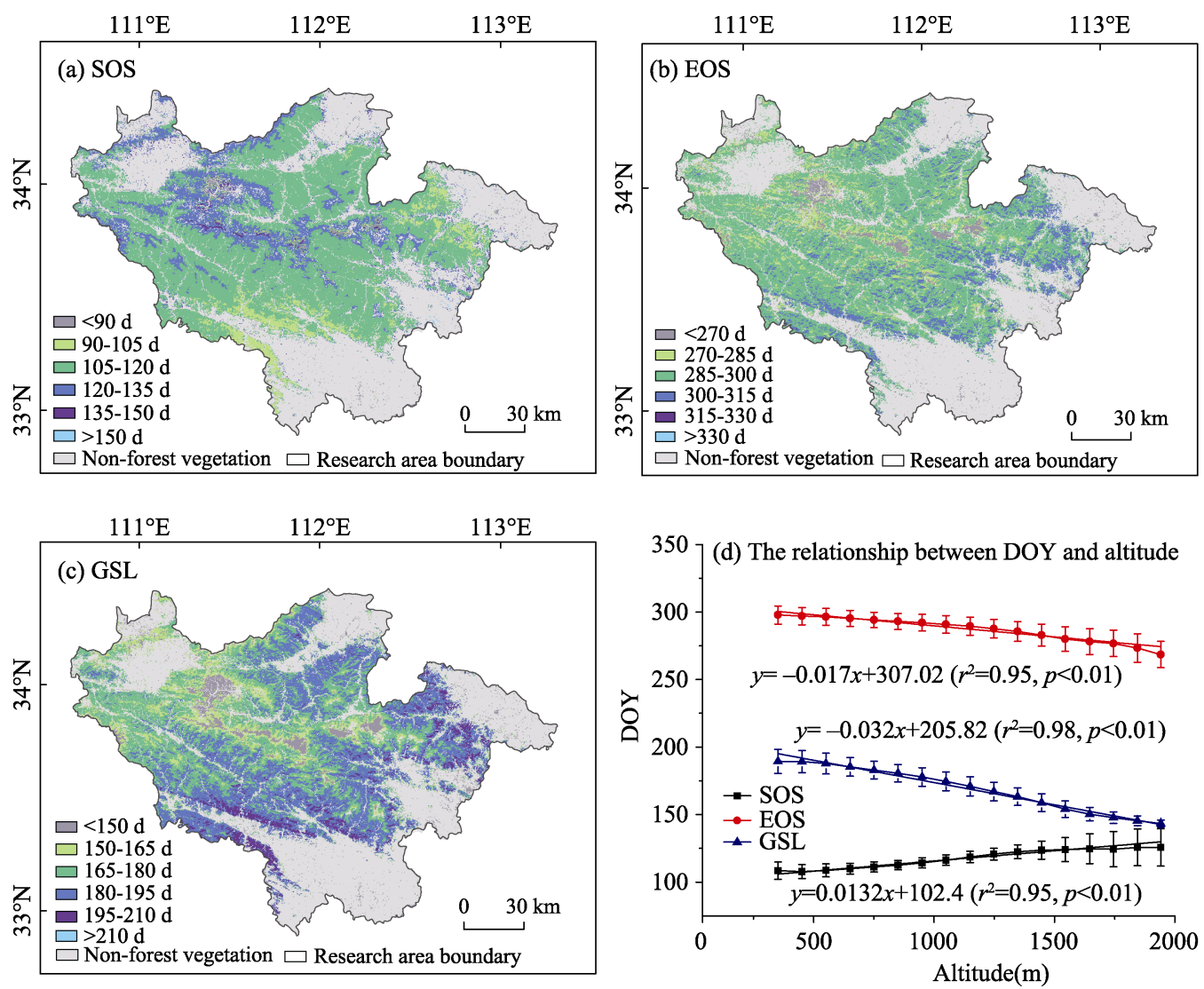

Figure 3 Spatial distributions of annual mean forest phenological parameters averaged over years in the Funiu Mountains and their relationships with altitude from 2000 to 2015 
GSLs in the eastern and southern lowlands were mostly within 195 to $210 \mathrm{~d}$, while those in the northwestern and central parts were mostly 165-180 and 150-165 d, respectively.

The changes in forest vegetation phenological parameters with altitude are shown in Figure $3 \mathrm{~d}$. With increasing altitude, SOS was significantly delayed at the rate of $1.3 \mathrm{~d} / 100 \mathrm{~m}\left(R^{2}\right.$ $=0.95, p<0.01)$, EOS was lengthened at $1.7 \mathrm{~d} / 100 \mathrm{~m}\left(R^{2}=0.95, p<0.01\right)$, and GSL was markedly shortened at $3.2 \mathrm{~d} / 100 \mathrm{~m}\left(R^{2}=0.98, p<0.01\right)$.

\subsection{Annual change in forest vegetation phenology}

The SOS of forest vegetation showed a delaying trend in most pixels $(76.57 \%)$, but the delaying area accounted for only $2.16 \%$ and was significantly scattered in the central part (Figure 4a). The pixels for which SOS was markedly lengthened were mainly concentrated in the southern, northern and eastern parts of the region, and those for which SOS was markedly delayed were primarily dispersed in the eastern part.

In most of the pixels, EOS was delayed (83.81\%); among these, EOS was significantly delayed by $6.38 \%$, which were mainly distributed in low-altitude areas in the southeastern part. The pixels for which EOS was not significantly delayed were concentrated in the central and northern regions, whereas the pixels in which EOS was significantly advanced were concentrated in the southern and eastern areas $(0.04 \%$; Figure $4 \mathrm{~b})$.
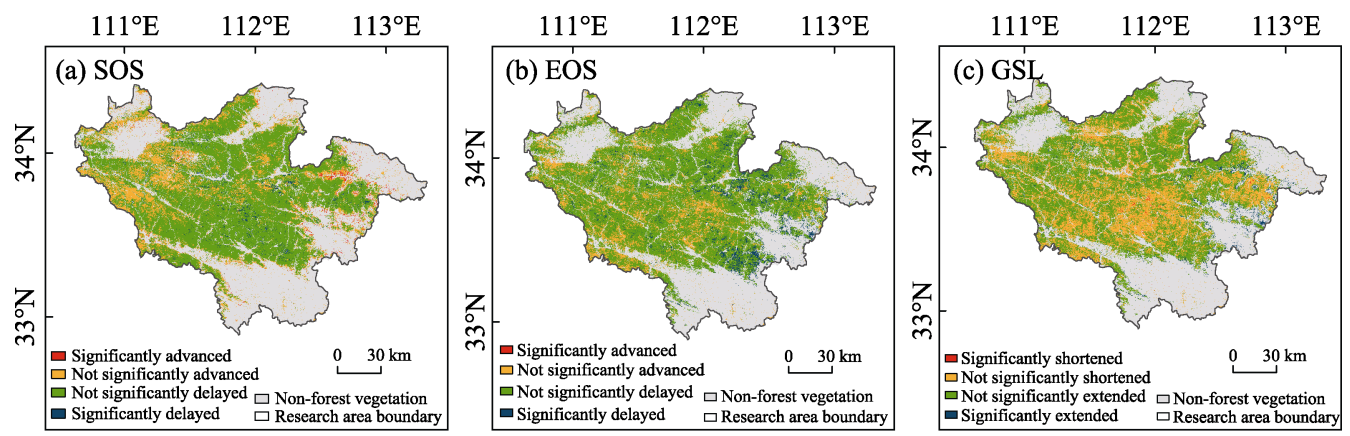

Figure 4 Spatial distributions of interannual variation in forest phenological parameters in the Funiu Mountains from 2000 to 2015

The changes in forest vegetation GSL were not significant; $60.85 \%$ of the pixels showed non-significant lengthening, and 36.25\% showed non-significant shortening (Figure 4c). The areas in which GSL was insignificantly shortened were mainly concentrated in the central, southern and eastern parts of the region. The pixels in which GSL was significantly lengthened $(0.36 \%)$ were mainly concentrated in the southeastern and northern parts.

\subsection{Response of forest vegetation phenology to change of temperature and precipitation}

\subsubsection{Effects of temperature and precipitation on SOS}

The spatial distributions of the partial correlation coefficients between SOS of forest vegetation and monthly average temperature and precipitation from February to April are shown in Figure 5. The partial correlation coefficients between SOS and monthly average temperature in February and March were mostly negative, indicating that SOS was delayed with decreasing temperature; however, the correlation coefficients became positive in April. 

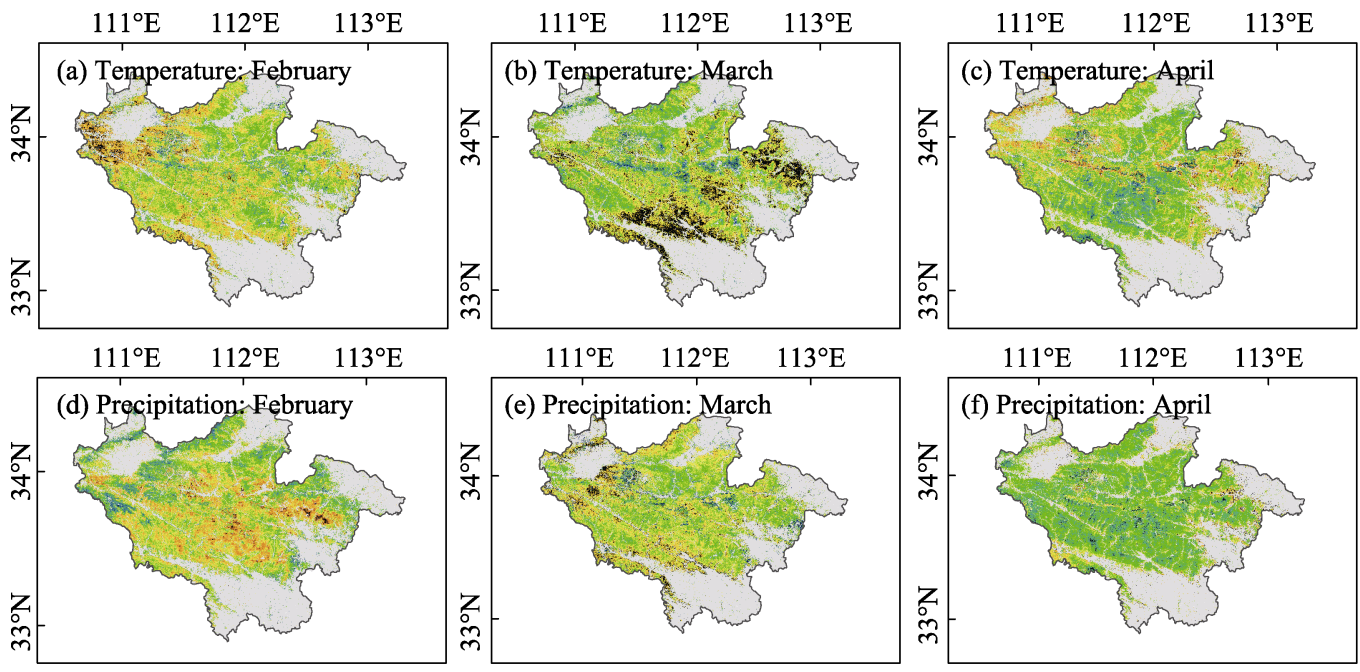

Partial correlation coefficient

$\begin{array}{llllllll}0.95-0.8-0.6-0.4-0.2 & 0 & 0.2 & 0.4 & 0.6 & 0.8 & 0.95 & \square\end{array}<0.05$

Figure 5 Spatial distributions of partial correlation coefficients between the start of the growing season (SOS) and February-April temperature and precipitation in the Funiu Mountains

In February, precipitation generally had a negative effect on SOS of forest vegetation at high elevations and a positive effect at lower elevations. The positive and negative partial correlation coefficients between SOS and precipitation exhibited uniform spatial distributions in March. In most regions, the partial correlation coefficients between SOS and precipitation were positive in April. The number of pixels with significant partial correlations between SOS and monthly average temperature was the greatest in March (13.94\%), indicating that the monthly average temperature in March had a relatively great impact on SOS.

Figure 6 shows the relationship between temperature and precipitation for the month with the maximum impact on the SOS of forest vegetation. The SOS of forest vegetation was mainly affected by the monthly average temperature in February and March $(37.24 \%$ and $37.25 \%$ of the pixels, respectively), and the decreasing monthly average temperature played
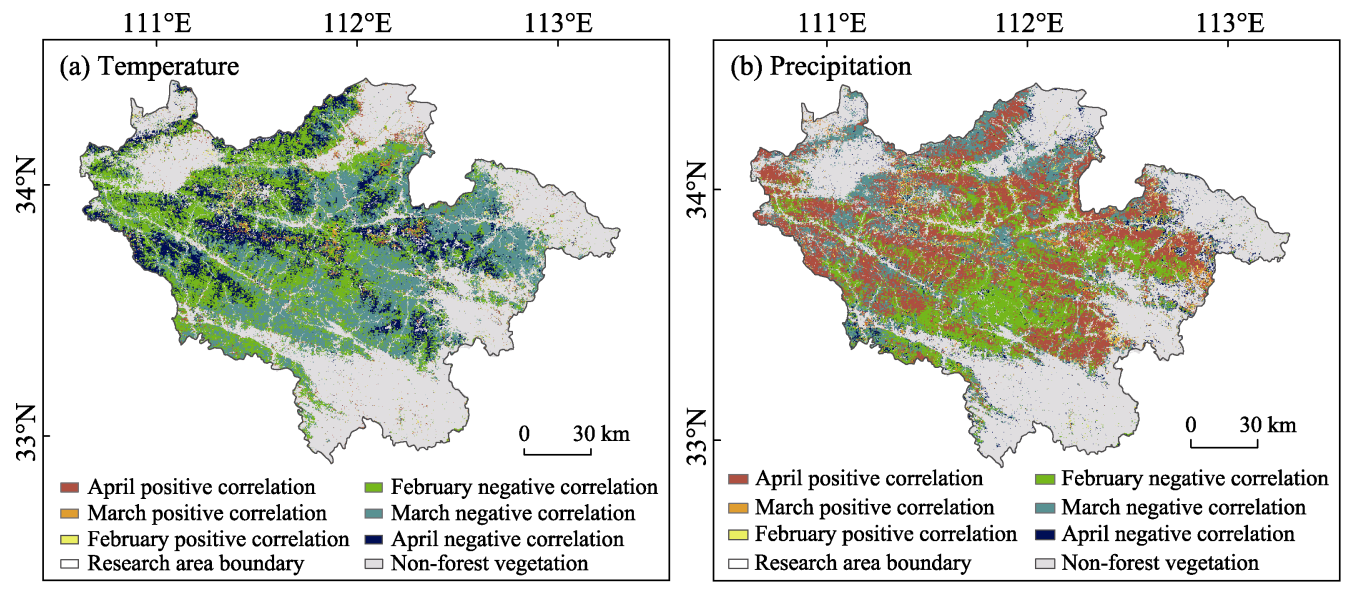

Figure 6 Spatial distributions of the start of the growing season (SOS) response to (a) temperature and (b) precipitation in the Funiu Mountains 
a large role in delaying SOS. Furthermore, the eastern and southern parts were primarily influenced by temperature decreases in March, while the northwestern part was mainly influenced by temperature decreases in February. In $22.90 \%$ of the pixels, SOS of forest vegetation was affected by the monthly average temperature; in April, $2.93 \%$ of the pixels were positively affected, while $19.97 \%$ were negatively affected.

The precipitation in April significantly affected SOS. In $37.25 \%$ of the pixels, SOS was delayed with increasing precipitation in April; in 4.6\%, SOS was lengthened with increasing precipitation in April. In $28.96 \%$ and $26.11 \%$ of the pixels, SOS was significantly negatively affected by the precipitation in February and March, respectively.

\subsubsection{Effects of temperature and precipitation on EOS}

The spatial distributions of the partial correlation coefficients between EOS and monthly average temperature and precipitation from September to November are shown in Figure 7. EOS was positively affected by temperature in September and negatively affected by temperatures in October and November. For precipitation, EOS of forest vegetation in the Funiu Mountains displayed a positive partial correlation with precipitation in September, and a few areas displayed significant positive partial correlations with precipitation in October and November. In terms of statistical significance, less than $5 \%$ of the pixels exhibited partial correlations between EOS of forest vegetation and monthly temperature in September, October, and November $(4.09 \%, 3.03 \%$ and $2.17 \%$ respectively). In September, $10.47 \%$ of the pixels exhibited significant partial correlations between EOS and precipitation, and these pixels were mainly distributed in the southwestern part of the study area. Only $2.88 \%$ and $1.30 \%$ of the pixels showed significant partial correlations between EOS and precipitation in October and November, respectively.
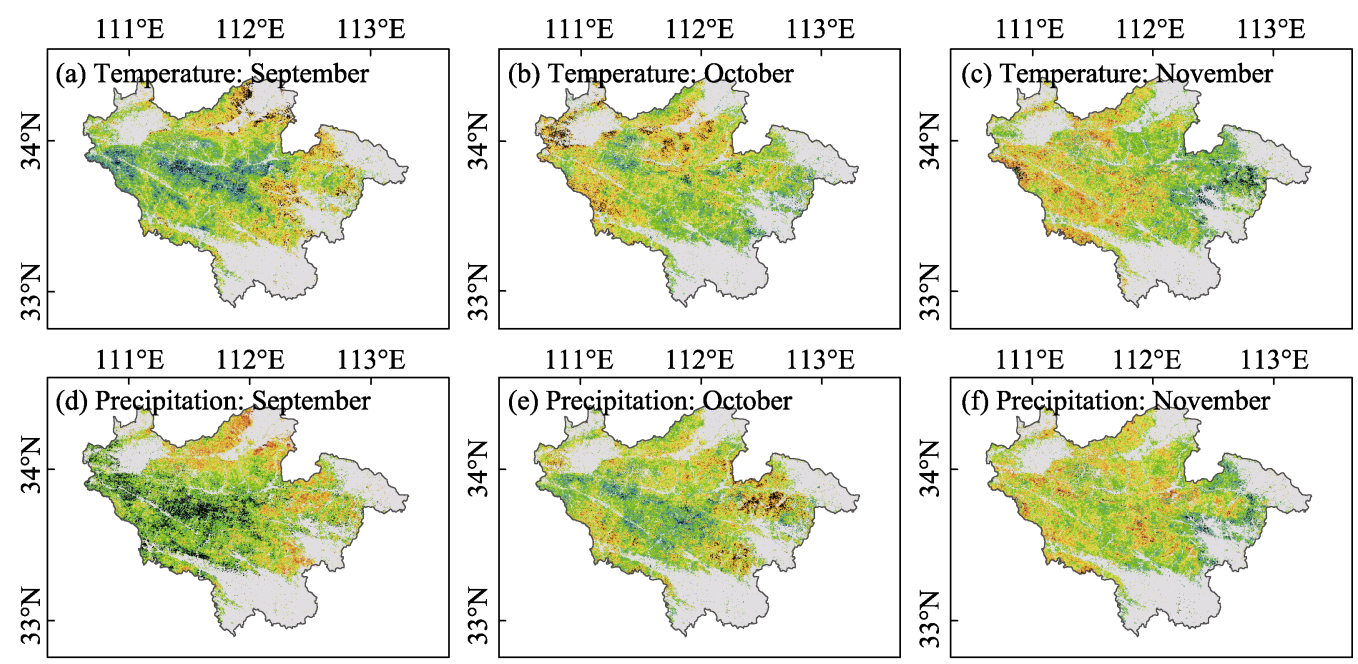

Partial correlation coefficient

$\begin{array}{llllllll}-0.95-0.8-0.6-0.4-0.2 & 0 & 0.2 & 0.4 & 0.6 & 0.8 & 0.95\end{array}$

Research area boundary $\square$ Non-forest vegetation $030 \mathrm{~km}$

Figure 7 Spatial distributions of partial correlation coefficients between the end of the growing season (EOS) and September-November temperature and precipitation in the Funiu Mountains

From the correlation coefficients between EOS of forest vegetation and temperature and precipitation (Figure 8), the number of pixels that the EOS were most negatively affected by monthly average temperature accounted for $42.87 \%$ and $23.27 \%$ of the total in September 
and October, respectively. Precipitation affected EOS most significantly in September; EOS was positively affected by precipitation in $64.99 \%$ of the pixels, indicating that the increase in precipitation in September delayed the EOS of forest vegetation. EOS was most significantly affected by precipitation in the eastern low-altitude region (16.94\% of the total area), and EOS was negatively correlated with precipitation in October.
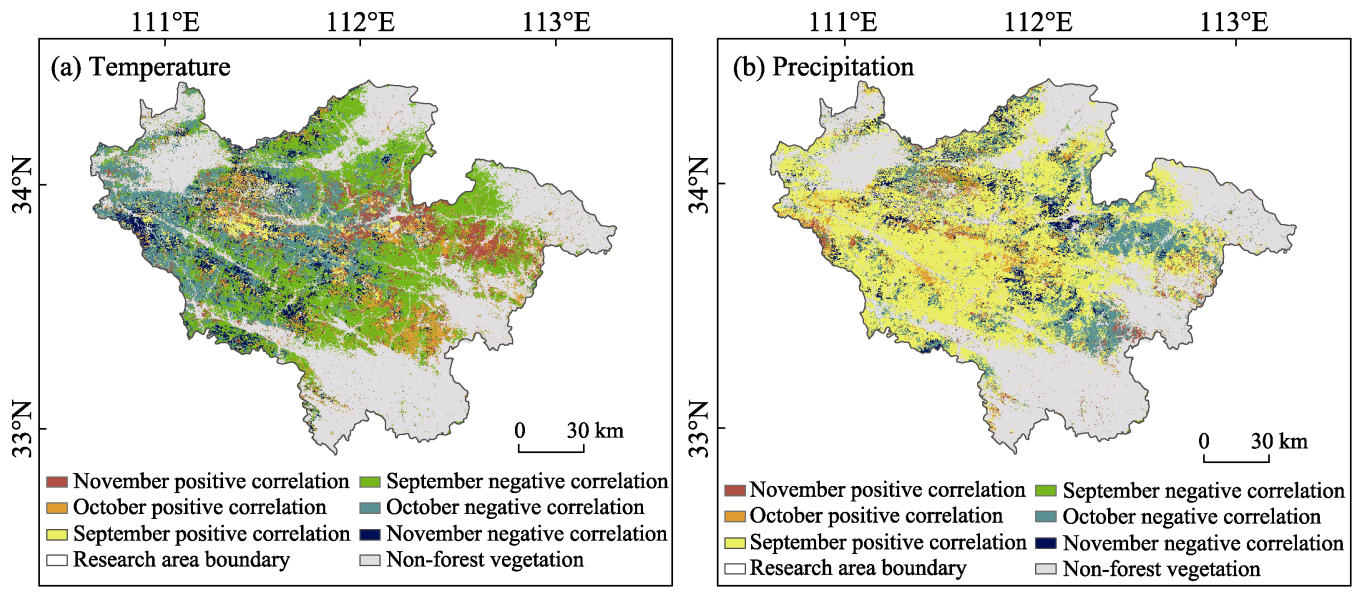

Figure 8 Spatial distributions of the end of the growing season (EOS) response to (a) temperature and (b) precipitation in the Funiu Mountains

\subsubsection{Response of GSL of forest vegetation to temperature and precipitation}

The GSL was negatively correlated with monthly average temperature from May through July in the central region at higher elevation, while a positive correlation was found in the marginal area. The monthly average temperatures in August and September had a negative effect on GSL in the eastern part and a positive impact in the western (Figure 9). In terms of precipitation, the increase in precipitation from May to July increased the GSL in most areas. The effect of precipitation in August and September on GSL showed obvious spatial heterogeneity; GSL was mainly negatively correlated with precipitation in the northern, southern and eastern parts and positively correlated with precipitation in the northwestern parts.

GSL was significantly correlated with monthly average temperature in August in $16.07 \%$ and September in $11.61 \%$ of the total pixels, respectively; these pixels were mainly distributed in the northern, eastern and southern parts. The GSL of forest vegetation was significantly correlated with precipitation in August in $18.14 \%$ of the total area, mainly distributed in the southern low-altitude region.

The relationship between the GSL of forest vegetation and the monthly average temperature and precipitation was more complex (Figure 10). The GSL in $40.46 \%$ of the total pixels was affected by monthly average temperature in September, and most were negatively correlated. The pixels that were significantly affected by the monthly average temperature in both June and July were similar, $11.61 \%$ and $18.68 \%$ of the total respectively. In the low-altitude marginal area, the GSL of forest vegetation increased with increasing temperature. The GSL of the northwestern part was mainly affected by precipitation in August and September positively, while that in the eastern was negatively correlated with precipitation in May and June. These results show that the effect of precipitation on GSL of forest vegetation had obvious spatial and temporal differences. 

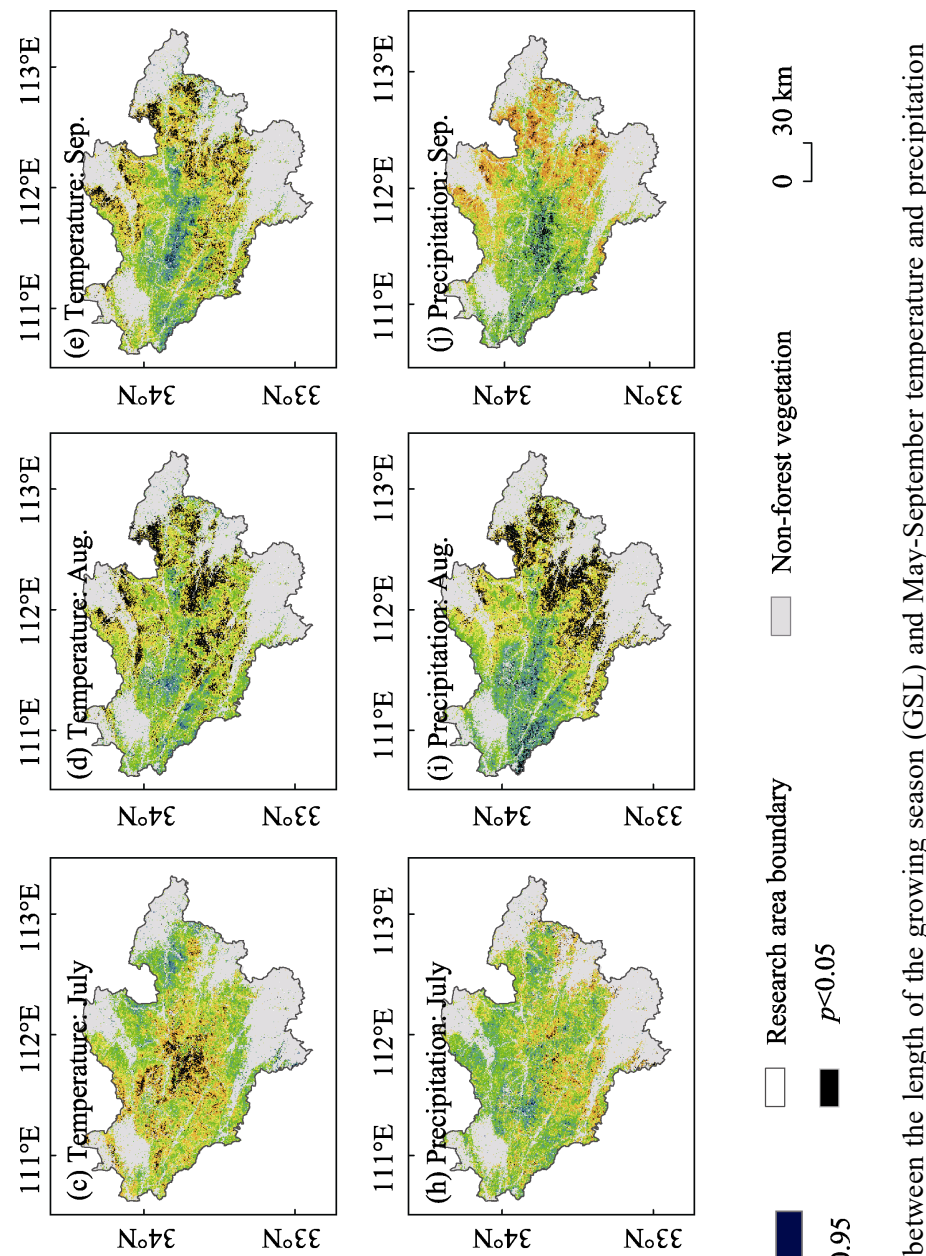

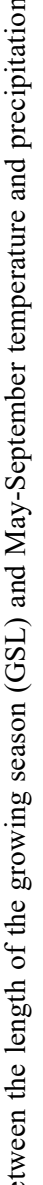
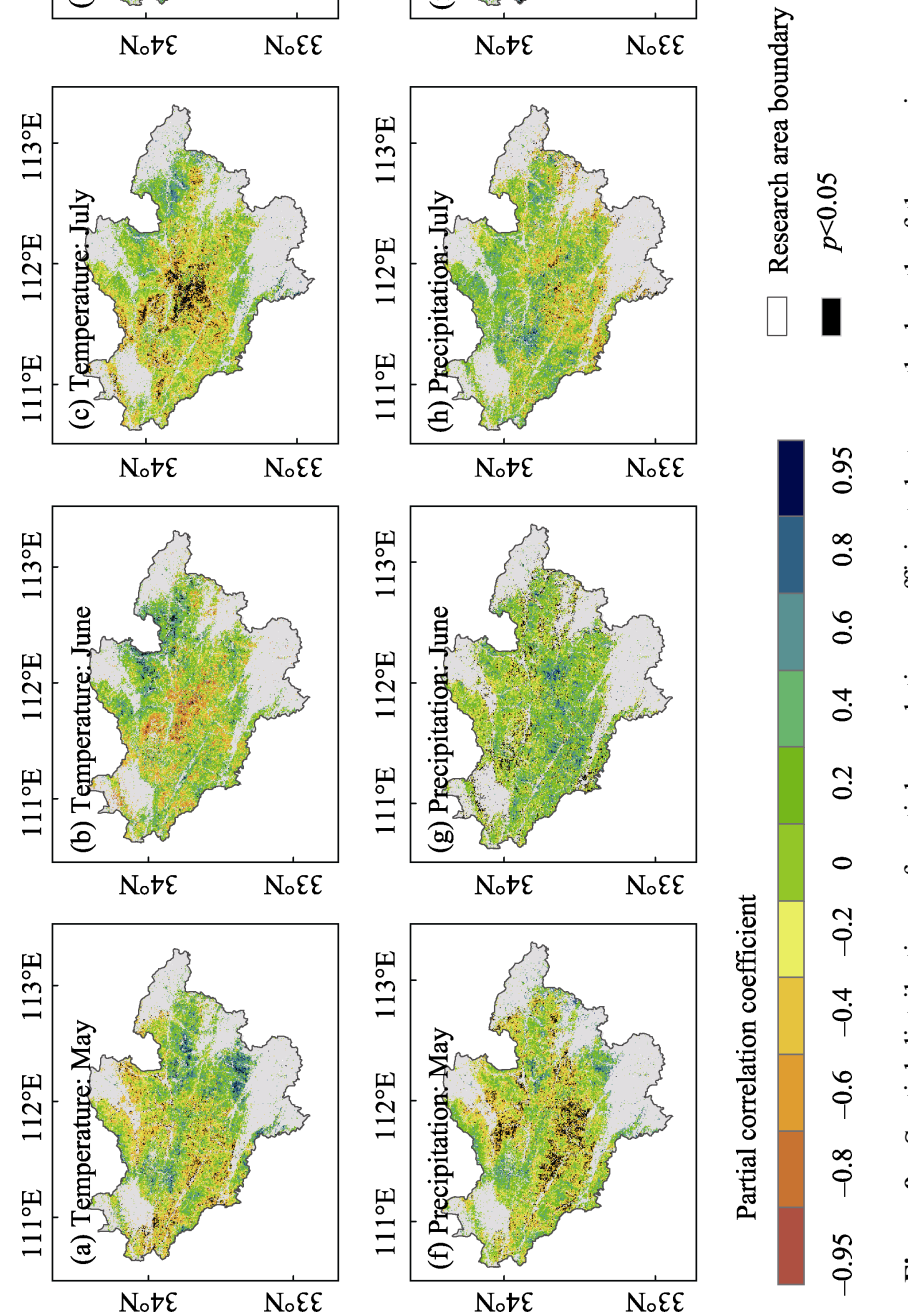

苞

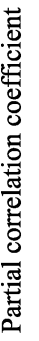

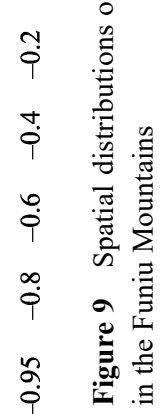



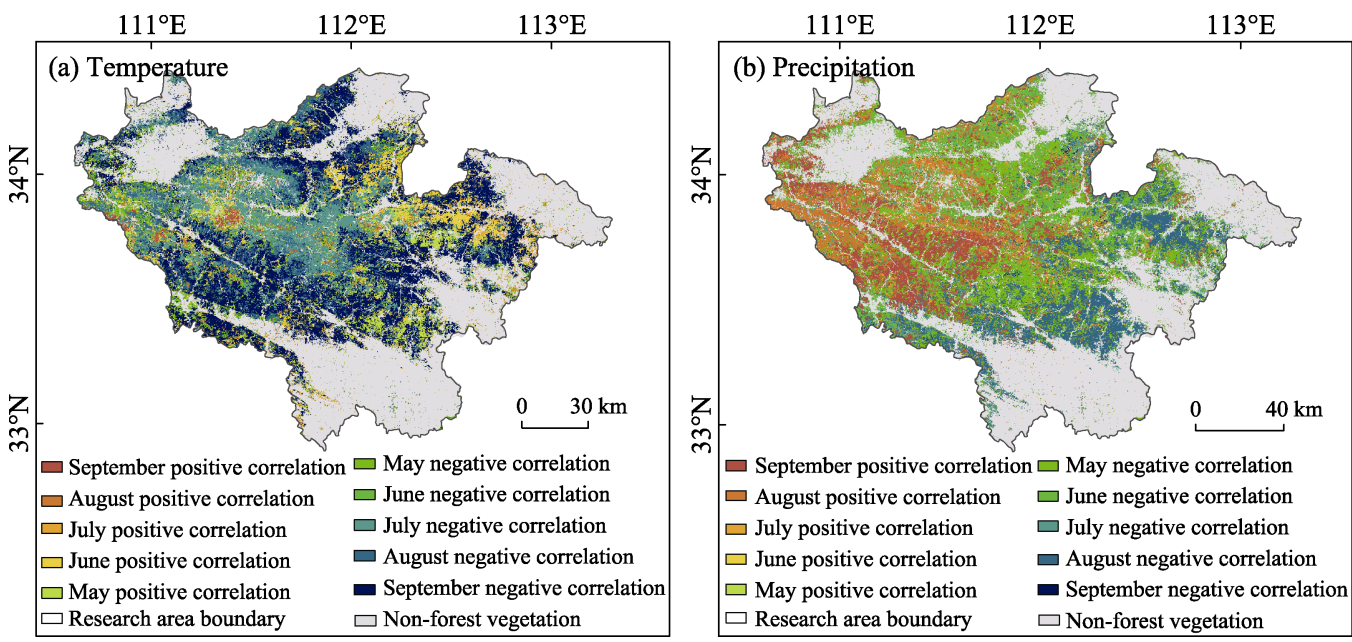

Figure 10 Spatial distribution of the length of the growing season (GSL) response to (a) temperature and (b) precipitation in the Funiu Mountains

\section{Discussion}

The results of this paper show that the SOS has been delayed during 2000-2015, consistent with the results of Xia et al. (2015) in other low-altitude areas in eastern Qinling Mountains. The delayed SOS may affect the growth of vegetation (Pau et al., 2011), decrease primary productivity (Richardson et al., 2013), and degrade forest ecosystem services; however, it can also have positive effects, including reducing the risk of spring frost (Dai et al., 2013). Compared to the advanced SOS in most of China's temperate regions, the delayed SOS in forest vegetation of the Funiu Mountains has distinct regional characteristics, the particularity can be explained by the traits of regional climate.

The results of this study indicate that the SOS, EOS and GSL of forest vegetation in the Funiu Mountains were affected by changes in both monthly average temperature and precipitation. The SOS of forest vegetation was most strongly influenced by monthly average temperature in February and March; decreasing temperature in spring delayed the SOS of forest vegetation. In contrast, the effect of precipitation on SOS of forest vegetation exhibited significant spatial differences. SOS was negatively correlated with spring precipitation in $54.33 \%$ of the pixels and positively correlated in the remaining pixels. The increase in precipitation in some areas provided the vegetation with sufficient moisture, increased its growth, and advanced the phenological phase. However, in some areas of coniferous forest, the increase in precipitation led to a decrease in temperature, resulting in a delay in the phenological phase ( $\mathrm{Zu}$ et al., 2016). In general, the relationships between the spring phenological phase of forest vegetation and temperature and precipitation in the Funiu Mountains are the same as those in other parts of China. However, the temperatures in February and March decreased significantly by $0.68^{\circ} \mathrm{C} / 10 \mathrm{a}$ and $0.25^{\circ} \mathrm{C} / 10 \mathrm{a}$, respectively, in contrast to the spring warming observed in most parts of the country (Liu, 2015). This "abnormal" change in spring temperature was the main factor leading to the delay of the SOS of Funiu Mountains.

Compared to SOS, temperature and precipitation affected EOS differently in different months. The EOS of forest vegetation was positively correlated with temperature and pre- 
cipitation in September; that is, EOS was delayed with increasing temperature and precipitation in September, consistent with results reported in northern China (Cong et al., 2013, Tao et al., 2017). However, this study also found that the increased precipitation in October and November led to advancement in EOS. This was attributed to the increased soil moisture, which affected the rate of photosynthesis of vegetation, promoted vegetation growth, and eventually caused EOS to advance ( $\mathrm{Ji}$ et al., 2005). At the same time, the phenological changes in spring and autumn may be affected by other environmental factors besides temperature and precipitation, including optical cycle, radiation intensity and carbon concentration (Xia et al., 2013, Cui et al., 2013, Forkel et al., 2015, Gill et al., 2015). Although these environmental factors have little effect on vegetation phenology compared to temperature and precipitation, they cannot be ignored.

The phenological data extracted from MODIS EVI have been compared with observational data. This study collected SOS and EOS data for elm in Neixiang and simon poplar in Lushi from 2000 to 2015. The average SOS date of elm fell in the last ten-day period of March, while the annual average EOS fell in the first ten-day period of September. The annual average SOS of simon poplar was during the first ten-day period of April, and the average EOS was in the second ten-day period of September. These dates are consistent with this study, in which the SOS and EOS of forest vegetation were found to be between DOY 90-120 and 270-300, respectively. Although the remote sensing data reflect the phenology of vegetation on a large scale, which differ from plant phenology observed in the field, the dates of SOS and EOS are consistent. The scale conversion between phenological data based on remote sensing and field observations is the focus of ongoing research.

\section{Conclusions}

In this study, the SOS, EOS and GSL of forest vegetation in the Funiu Mountains were extracted from MODIS EVI data along with temperature and precipitation data from 2000-2015. The spatial and temporal changes in these phenological parameters were analyzed systematically, and the relationships between the phenological parameters and temperature, and precipitation were evaluated. The conclusions are as follows.

(1) Within the Funiu Mountains, SOS was mostly concentrated within DOY 105-120, while EOS was mostly concentrated within DOY 285-315. GSL primarily ranged between 165 and $195 \mathrm{~d}$. Based on the annual trends in phenological parameters over the 16-year study period, areas with no significant delay in SOS and EOS accounted for $74.41 \%$ and $77.43 \%$ of the total area, respectively, and areas where EOS was not significantly lengthened accounted for $60.85 \%$ of the total area. Phenological period was closely related to elevation; SOS and EOS were delayed with increasing elevation, while GSL was increased.

(2) Over the past 16 years, the average temperature and precipitation in the Funiu Mountains have exhibited the following trends. Temperature in February and March has decreased significantly, while temperature in October has increased. Precipitation in June and October has decreased significantly. Between February and March, the temperature has mainly decreased, while the precipitation has primarily increased. Between May and September, the temperature has mainly increased, while precipitation has mainly decreased. Between September and November, the temperature primarily increased, while precipitation mainly decreased. 
(3) In the Funiu Mountains, the delay in SOS was primarily attributed to the decreased temperature in March, and the delay in EOS was primarily attributed to the increased precipitation in September. The increase in GSL was primarily attributed to the increased temperature between July and September.

\section{References}

And D R H, Frans L M, 2006. Regional Kendall test for trend. Environmental Science \& Technology, 40(13): 4066-4073.

Chen X, Yu R, 2007. Spatial and temporal variations of the vegetation growing season in warm-temperate eastern China during 1982 to 1999. Acta Geographica Sinica, 62(1): 41-51. (in Chinese)

Cong N, Wang T, Nan H et al., 2013. Changes in satellite-derived spring vegetation green-up date and its linkage to climate in China from 1982 to 2010: A multi-method analysis. Global Change Biology, 19(3): 881-891.

Cui Y P, 2013. Preliminary estimation of the realistic optimum temperature for vegetation growth in China. Environmental Management, 52(1): 151-162.

Dai J, Wang H, Ge Q, 2013. The decreasing spring frost risks during the flowering period for woody plants in temperate area of eastern China over past 50 years. Journal of Geographical Sciences, 23(4): 641-652.

Ding S, Lu X, 2006. Comparison of plant flora of Funiu Mountain and Jigong Mountain natural reserves. Geographical Research, 25(1): 62-70. (in Chinese)

Fan Y, Hu N, Ding S et al., 2008. A study on the classification of plant functional types based on the dominant herbaceous species in forest ecosystem at Funiu Mountain national natural reserve. Acta Ecologica Sinica, 28(7): 3092-3101. (in Chinese)

Forkel M, Migliavacca M, Thonicke K et al., 2015. Codominant water control on global interannual variability and trends in land surface phenology and greenness. Global Change Biology, 21(9): 3414-3435.

Gill A L, Gallinat A S, Sanders-Demoot R et al., 2015. Changes in autumn senescence in northern hemisphere deciduous trees: A meta-analysis of autumn phenology studies. Annals of Botany, 116(6): 875-888.

Ivan N B, Alexander A M, Mikhail Y et al., 2018. Climate warming as a possible trigger of Keystone Mussel population decline in Oligotrophic Rivers at the continental scale. Scientific Reports, 8: 35 . doi: 10.1038/s41598-017-18873-y

Ji J, Huang M, Liu Q, 2005. Modeling studies of response mechanism of steppe productivity to climate change in middle latitude semiarid regions in China. Acta Meteorologica Sinica, 63(3): 257-266. (in Chinese)

Jordan R M, Nathan J S, Aimée T C et al., 2017. Elevation alters ecosystem properties across temperate treelines globally. Nature, 542: 91-95.

Jong R D, Bruin S D, Wit A D et al., 2011. Analysis of monotonic greening and browning trends from global NDVI time-series. Remote Sensing of Environment, 115(2): 692-702.

Jönsson P, Eklundh L, 2002. Seasonality extraction by function fitting to time-series of satellite sensor data. IEEE Transactions on Geoscience and Remote Sensing, 40(8): 1824-1832.

Jönsson P, Eklundh L, 2004. Timesat: A program for analyzing time-series of satellite sensor data. Computers \& Geosciences, 30(8): 833-845.

Julien Y, Sobrino J A, 2009. Global land surface phenology trends from GIMMS database. International Journal of Remote Sensing, 30(13): 3495-3513.

King D A, 2004. Environment-climate change science: Adapt, mitigate, or ignore? Science, 303(5655): $176-177$.

Kong D, Zhang Q, Huang W et al., 2017. Vegetation phenology change in Tibetan Plateau from 1982 to 2013 and its related meteorological factors. Acta Geographica Sinica, 72(1): 39-52. (in Chinese)

Liu F, 2015. Temporal-spatial variations of temperature in Chinese inland based on GIS and multivariate statistical method [D]. Lanzhou: Lanzhou University.

Liu Z, Li L, Mc Vicar T R et al., 2008. Introduction of the professional interpolation software for meteorology data: ANUSPLINN. Meteorological Monthly, 34(2): 92-100. (in Chinese)

Luo Z, Yu S, 2017. Spatiotemporal variability of land surface phenology in China from 2001-2014. Remote Sens., 9: 65. doi: 10.3390/rs9010065.

Ma J, 2004. Laws of soil vertical variations on southern slope of Funiu Mt.: Simultaneous study on north boundary of subtropical zone. Acta Geographica Sinica, 59(6): 998-1011. (in Chinese)

Ma X, Chen S, Deng J et al., 2016. Vegetation phenology dynamics and its response to climate change on the 
Tibetan Plateau. Acta Prataculturae Sinica, 25(1): 13-21. (in Chinese)

$\mathrm{Mu}$ S, Li J, Chen Y et al., 2012. Spatial differences of variations of vegetation coverage in Inner Mongolia during 2001-2010. Acta Geographica Sinica, 67(9): 1255-1268. (in Chinese)

Nemani R, Keeling C D, Hashimoto H et al., 2003. Climate-driven increases in global terrestrial net primary production from 1982 to 1999. Science, 300(5625): 1560-1563.

Pau S, Wolkovich E M, Cook B I et al., 2011. Predicting phenology by integrating ecology, evolution and climate science. Global Change Biology, 17(12): 3633-3643.

Richardson A D, Keenan T F, Migliavacca M et al., 2013. Climate change, phenology, and phenological control of vegetation feedbacks to the climate system. Agricultural and Forest Meteorology, 169(3): 156-173.

Sen P K, 1968. Estimates of the regression coefficient based on Kendall's Tau. Journal of the American Statistical Association, 63(324): 1379-1389.

Song C, 1994. Scientific Survey of the Funiu Mountain Nature Reserve. Beijing: China Forestry Publishing House. (in Chinese)

Tan J, Li A, Lei G, 2016. Contrast on Anusplin and Cokriging meteorological spatial interpolation in southeastern margin of Qinghai-Xizang Plateau. Plateau Meteorology, 35(4): 875-886. (in Chinese)

Tao Z, Wang H, Liu Y, 2017. Phenological response of different vegetation types to temperature and precipitation variations in northern China during 1982-2012. International Journal of Remote Sensing, 38(11): 3236-3252.

Wang G, Deng W, Yang Y et al., 2011. The advances, priority and developing trend of alpine ecology. Journal of Mountain Science, 29(2): 129-140. (in Chinese)

Wang Y, Tian Q, Huang Y, 2013. NDVI difference rate recognition model of deciduous broad-leaved forest based on HJ-CCD remote sensing data. Spectroscopy and Spectral Analysis, 33(4): 1018-1022. (in Chinese)

Xia H, Li A, Zhao W et al., 2015. Spatiotemporal variations of forest phenology in the Qinling zone based on remote sensing monitoring, 2001-2010. Progress in Geography, 34(10): 1297-1305. (in Chinese)

Xia J, Chen J, Piao S et al., 2014. Terrestrial carbon cycle affected by non-uniform climate warming. Nature Geoscience, 7(3): 173-180.

Xia J Y, Wan S Q, 2013. Independent effects of warming and nitrogen addition on plant phenology in the Inner Mongolian steppe. Annals of Botany, 111(6): 1207-1217.

Xu Y, Dai J, Wang H et al., 2015. Variation characteristics of main phenophases of natural calendar and analysis of responses to climate change in Harbin in 1985-2012. Geographical Research, 34(9): 1662-1674. (in Chinese)

Yu F, Zheng X, Gu X et al., 2008. Comparative study on spatial interpolation of climate elements precision in complex mountainous environment. Journal of Guizhou Meteorology, 32(3): 3-6. (in Chinese)

Zhang B, Yao Y, 2016. Implications of mass elevation effect for the altitudinal patterns of global ecology. Journal of Geographical Sciences, 26(7): 871-877.

Zhang C, Nan Y, Zhao Y, 2016. Study on vegetation classification based on multi-temporal HJ-1 CCD data: The Changbai Mountain area as a case. Geography and Geo-Information Science, 29(5): 41-44. (in Chinese)

Zhang J, Wang Y, Zhu L et al., 2016. Study on change of northern subtropical border in mountainous regions in western Henan province. Journal of Henan University: Natural Science, 46(1): 40-49. (in Chinese)

Zhang X, Friedl M C, Strahler A, 2004. Climate controls on vegetation phenological patterns in northern mid- and high latitudes inferred from MODIS data. Global Change Biology, 10(7): 1133-1145.

Zhang X, Zhu W, Cui Y et al., 2016. The response of forest dynamics to hydro-thermal change in Funiu Mountain. Geographical Research, 35(6): 1029-1040. (in Chinese)

Zheng J, Ge Q, Hao Z et al., 2012. Changes of spring phenodate in Yangtze River Delta region in the past 150 years. Acta Geographica Sinica, 67(1): 45-52. (in Chinese)

Zhou L, Tucker C J, Kaufmann R K et al., 2001. Variations in northern vegetation activity inferred from satellite data of vegetation index during 1981 to 1999. Journal of Geophysical Research Atmospheres, 106(D17): 20069-20084.

Zhu K, Wan M, 1999. Phenology. Changsha: Hunan Education Publishing House. (in Chinese)

Zhu L, Xu L, 2011. Analysis of effects of global change on terrestrial ecosystem. Areal Research and Development, 30(2): 161-164. (in Chinese)

Zhu Z, Piao S, Myneni R B et al., 2016. Greening of the earth and its drivers. Nature Climate Change, 6(8): 791-796.

$\mathrm{Zu} \mathrm{J}$, Yang J, 2016. Temporal variation of vegetation phenology in northeastern China. Acta Ecologica Sinica, 36(7): 2015-2023. (in Chinese) 